The paper concludes that if the new forms of pension provision, with their associated uncertainties, become widespread, or if voluntary membership of pension schemes leads to a reduction in the provision made for retirement, an adequate safety net in the form of the Basic State pension is essential. The gradual erosion of National Insurance benefits, as evidenced by the deterioration of the State pension relative to earnings and the stated views of certain politicians, is viewed as highly regrettable.

\title{
THE ACTUARY'S ROLE IN DETERMINING PENSION FUND INVESTMENT STRATEGY
}

\author{
BY I. W. WOODS
}

(Synopsis of a paper presented to the Society on 11 April 1989)

THE paper outlines some of the practical issues currently facing actuaries in their current involvement in assisting clients define pension fund investment strategy.

Increasingly pension funds in the UK are considering the adoption of an investment strategy geared towards the particular circumstances of the fund and its sponsoring company.

The major reason for the move towards customized investment strategies has been the acceptance amongst corporate financial management of the importance which pension fund assets play in company finances.

Much of the work of the profession to date has involved reviewing past investment performance although little thought seems to have been applied in actually identifying whether or not the performance yardsticks being applied are really valid. Contrary to accepted business practice, companies have expended much of their energy reviewing the return on a substantial portion of their assets without a clear 'Business Plan' having been pre-determined.

The profession is ideally suited to assist in devising the long-term strategy of a pension fund although it is considered that conflicts of interest would arise between the actuarial adviser and the investment adviser should actuaries become involved in the short-term tactical asset allocation designed to take advantage of short-term movements in markets.

There should be a clear division of responsibilities between the liability-led nature of the advice on long-term strategy, which would be the responsibility of the actuary, and tactical asset allocation which would be the responsibility of the investment adviser.

It is suggested that the investment objectives for a pension fund should be based on the sponsoring company's business expectations for its pension fund. In this way, the objective of the pension fund's investment strategy can be directly related to the achievement of the company's strategic business objective for its pension fund. 
It also allows the introduction of a meaningful and objective definition of 'risk'. 'Risk' is often used indiscriminately in statements of investment policy or investment objectives. By introducing the concept of a Business Objective for the pension fund, the 'risk' inherent in a particular investment strategy can thus be related objectively to the probability of not achieving the stated Business Objective.

Such an approach can be criticised on the grounds that it views the investment strategy purely from the viewpoint of the company rather than the members of the pension fund. The interests of the members can and should be allowed for typically by including the attainment and continuation of minimum funding ratios within the Business Objectives.

Much of the discussion on pension fund investment strategy has, to date, involved the matching assets to liabilities. By relating investment strategy to the achievement of the Business Objective, account can also be taken of the likely range of cost which the employer is prepared to accept and the employer's degree of risk averseness relative to the likely range of cost.

In identifying the most appropriate long-term investment strategy, use is increasingly being made of modelling techniques applied to both the fund's assets and liabilities.

The impact of different investment strategies on the financial factors influencing pension funds such as contribution rates and funding ratios can be examined by modelling probability distributions of both the assets and the liabilities incorporating consistent projections of future inflation.

The technique also permits the impact of different valuation bases to be assessed. For example, the likelihood of a particular asset mix resulting in the emergence of a statutory excessive surplus can be assessed using the prescribed bases for such calculations whilst the impact on the ongoing contribution rate can be assessed using a different basis.

In this way a clear insight is obtained on the degree of 'risk' involved in pursuing a particular investment strategy.

The move of pension funds towards investment strategies geared towards their own circumstances has implications for the monitoring of investment performance. The acceptance by a pension fund of a long-term asset mix suggests that the basic yardstick against which performance should be judged is the performance of a passive portfolio invested in line with the long-term asset mix and achieving Index returns in each market, rather than the performance of the 'average pension fund'.

Performance monitoring will thus concentrate, in future, on the added value arising as a result of tactical divergences from the strategic long-term asset mix and of stock selection within markets relative to the performance of predetermined indices. 